\title{
Management of malignant tumors of the anterior and anterolateral skull base
}

\author{
Thomas C. Origitano, M.D., Ph.D., Guy J. Petruzzelli, M.D., Ph.D., \\ Darl VAndevender, M.D., AND Bahman EMaMi, M.D. \\ Departments of Neurological Surgery, Otolaryngology-Head and Neck Surgery, Radiation Oncology, \\ and Divisions of Plastic and Reconstructive Surgery, Department of Surgery, Loyola University \\ Medical Center, Maywood, Illinois
}

\begin{abstract}
Object. Malignant tumors of the skull base represent a group of diverse and infrequent lesions. Comprehensive oncological management requires a multidisciplinary team of neurological surgeons, otolaryngologists, radiation oncologists, plastic surgeons, and medical oncologists. The authors describe an institutional experience in performing 54 combined anterior-anterolateral cranial base resections for malignant disease.

Methods. The technical considerations for preoperative workup, surgical approach, resection, and reconstruction are outlined and illustrated. Considerations for complication management and avoidance are detailed.

Conclusions. Overall mortality $(0 \%)$ and morbidity rates $(18 \%)$ are acceptable. The influence on the natural history of the disease process is an ongoing study.
\end{abstract}

KEY WORDS • skull base tumor • multidisciplinary approach • complication analysis

The vast majority of malignant cranial base tumors arise in the anterior or anterolateral skull base, originating in the paranasal sinuses or nasal cavity. Examples of these include esthesioneuroblastoma, sinonasal carcinoma, adenocarcinoma, squamous cell carcinoma, neuroendocrine carcinoma, sarcoma, chondrosarcoma, and other sinonasal malignancies. All are relatively rare, constituting approximately less than $1 \%$ of all malignant tumors. Because of their presenting locations and often indolent initial course, their surgical management is challenging.

The orbital regions, optic apparatus, anterior cranial base dura, brain, cavernous sinus, and their neurovascular components are often involved. Patients frequently present late in the disease process, with complaints of symptoms secondary to the indolent course of the lesions. Depending on the lesion type and location, symptom complexes often involve nasal obstruction, epistaxis, sinus headache, nasal pain, trismus, facial numbness or pain, tooth pain, and ocular complaints of pain, exophthalmos, and ophthalmoplegia.

Optimum management of this diverse group of patients and lesions is not universally accepted. We present our institutional approach based on experience performing 100 anterior and anterolateral cranial-based operations, 54 of which were to treat malignant disease (Table 1).

Abbreviations used in this paper: CSF = cerebrospinal fluid; $\mathrm{CT}=$ computerized tomography; $\mathrm{MR}=$ magnetic resonance.

\section{CLINICAL MATERIAL AND METHODS}

\section{Management of Skull Base Malignant Tumors}

Workup and Evaluation. Patients who are referred to the cranial base service are evaluated by both the neurological surgeon and otolaryngologist sequentially. Radiological evaluation consisting of contrast-enhanced MR imaging and coronal/axial CT scanning of the frontal sinus is performed. A thorough head and neck examination with flexible endoscopy is performed.

Whenever possible, a transnasal biopsy sample is obtained. Once malignancy is confirmed, a staging metastatic workup consisting of chest, abdomen, and pelvis CT scans is performed. The results of these studies are considered in conjunction with whether an en bloc resection with tumor margins can be performed; these factors are used to determine the roles of surgical management and perioperative chemo- and radiotherapy. Overall management of malignant skull base lesions requires a coordinated effort by an otolaryngologist, neurological surgeon, head and neck radiation oncologist, solid-tumor medical oncology specialist, and a plastic surgeon experienced in microvascular free-tissue transfer reconstruction.

Surgical Management. The goal of surgery is an oncological en bloc resection defined as the lesion plus normal margin. Presently, with the advent of computer-assisted surgical navigation and radiosurgery/therapy/intensitymodulated radiotherapy, this definition is considered anew. The limitation of undertaking this surgical approach is often the functional consideration of the marginal anatomy. 
TABLE 1

Summary of malignant skull base lesions treated at our institution

\begin{tabular}{lc}
\hline \hline \multicolumn{1}{c}{ Tumor Type } & No. of Cases \\
\hline myoepithelial carcinoma & 2 \\
esthesioneuroblastoma & 13 \\
chondrosarcoma & 1 \\
squamous cell carcinoma & 7 \\
adenocarcinoma & 9 \\
neuroendocrine carcinoma & 1 \\
melanoma & 3 \\
sinonasal carcinoma & 3 \\
adenoid cystic & 8 \\
hemangiopericytoma & 1 \\
malignant paraganglion & 1 \\
sarcoma & 1 \\
spindle cell carcinoma & 1 \\
malignant meningioma & 3 \\
total & 54 \\
\hline
\end{tabular}

The ability to deliver high doses of radiation extends the margin if radiosensitive structures-for example, optic nerve - can be juxtaposed away from the margins by transposition or separation of the defects by using small adipose tissue spacers. Furthermore, the ability to reconstruct the defects by using durable vascularized tissue enhances the delivery of optimum adjuvant therapies.

\section{Surgery-Related Considerations}

Surgery consists of three components: approach, definitive resection, and reconstruction. The three main approaches are craniofacial, ${ }^{1,3,6,7,13}$ extended subfrontal, ${ }^{21,24,25}$ and transfacial. ${ }^{8,19,27}$ Approach-related complications are common and in general are related to bridging the interface between the paranasal sinuses and intracranial/intradural spaces.

Transfacial approaches consist of combinations of transoral, transpalatal, transmaxillary, lateral rhinotomy, and midface degloving. As stand-alone procedures for malignancy, their use is limited to cases in which the superior margin of the lesion can be safely attained.

The standard surgical procedures are the craniofacial resection (combining a bifrontal or orbitozygomatic craniotomy with a transfacial approach) and the extended subfrontal approach in which a bifrontal craniotomy is perfromed in conjunction with a very low aggressive bilateral supraorbital osteotomy.

All patients undergoing resection receive counseling regarding the loss of smell and its effect on the perception of taste. The possibility of a temporary tracheostomy is also detailed, although it is seldom required.

Perioperative antibiotic therapy consists of ceftriaxone ( $1 \mathrm{~g} /$ hour for 8 hours). Clindamycin (900 mg) irrigation ${ }^{2}$ is administered prior to dural opening and once the dura is reconstituted.

On the operating table patients are positioned supine in three-point pin fixation placed behind the ears. The head is extended and the table angled head-up to optimize drain autoretraction. Tarsorrhaphy is performed for temporary eyelid closure. Prior to pin fixation, a spinal drain is placed but kept closed during all extradural procedures. The head, face, abdomen (for potential fat graft and rectus flap), and thigh (for potential fascia lata graft) are prepared and draped to accommodate multiple approach and reconstructive scenarios.

\section{Patient Population}

Fifty-four patients ( 32 males and 22 females, mean age $49 \pm 3$ years) harbored malignant lesions. Frameless stereotaxis ${ }^{20}$ was performed preoperatively as an adjuvant for navigation in $48(88 \%)$ cases. Registration was performed prior to preparation and draping. Reregistration divots were placed on the skull after the skin incision was made. Using both anatomical and registration landmarks, accuracy was checked prior to skin incision. The merging of preoperative MR images and CT scans was performed whenever possible. Craniofacial resection was performed in 41 cases (76\%), extended subfrontal in $12(22 \%)$, and transfacial only in the remaining case $(2 \%)$. Primary operations were performed in 46 cases $(85 \%)$, and reoperations in eight cases (15\%). Six orbital exenterations and 11 rectus muscle-fat free flap procedures were performed. ${ }^{4}$ Pericranium-assisted or fascia lata-assisted dural reconstruction $^{9,23,31}$ was performed in 48 cases $(88 \%)$; cranial base reconstruction was conducted using vascularized pericranial flap transposition sutured to the remnant base in 48 cases (88\%). Temporalis muscle transpositions were conducted in seven cases (13\%). Cranial closures were reinforced superiorly using fibrin glue. Drains were placed in the epidural and subgaleal spaces and in any site at which graft material had been harvested.

At the completion of each procedure, the nasal cavity was inspected endoscopically and reinforced using fat, fibrin glue, packs, and nasal trumpets. The patient was kept in the operating room if the epidural drain did not hold suction. This test demonstrated adequate sealing of the intracranial space. In cases in which the seal was not held, additional transnasal endoscopic packing was performed. Spinal drainage was discontinued in the operating room. If necessary, a feeding tube was passed through one nasal trumpet. The neurosurgical approach has been described in detail elsewhere. ${ }^{16-18,26}$

Patients are managed postoperatively in a neurosurgical intensive care unit. Follow-up CT scanning is performed within 24 hours to determine the presence of epidural air and occult hemorrhage and edema. Dilation is maintained for 2 weeks. Epidural drains are removed within 24 to 48 hours, after which the subgaleal drain is extracted. Nasal packings are slowly discontinued beginning on Day 4 . Patients are released from the hospital between Days 5 and 7.

Outpatient follow up is conducted in a multidisciplinary clinic. Patients undergo weekly endoscopic surveillance to assess healing and facilitate debridement and sinus drainage. Evaluations to determine the need for postoperative radio- and chemotherapy are performed simultaneously. It is important to continue endoscopic surveillance during and after radiotherapy to avoid complications secondary to radiation-induced sinusitis.

\section{RESULTS}

There were no surgery-related deaths. Complications occurred in 10 patients (18\%). All patients underwent postoperative radiotherapy. A summary of complications 


\section{Malignant tumors of the anterior and anterolateral skull base}

is provided in Table 2. Primary operations were associated with eight complications (17\%) and reoperations with two complications (25\%). Complications occurred between Days 1 and 14 (mean postoperative occurrence $7 \pm$ 3 days).

\section{ILLUSTRATIVE CASE}

History. This 30-year-old man had a several-month history of nasal congestion, as well as right airway obstruction treated using over-the-counter nose sprays and allergy medications. Subsequently, he began to develop right-sided orbital pain and headache. He underwent endoscopy of the sinus, and an intranasal mass was demonstrated.

Examination. Examination revealed mild exophthalmos of the right eye, double vision, and decreased visual acuity of the right eye (Fig. 1). Sinonasal endoscopy demonstrated a large friable granular mass filling the posterior and superior right nasal cavity. A biopsy sample was obtained, and examination revealed basaloid-squamous cell carcinoma. A CT study of the sinuses revealed a softtissue mass and erosion of the medial wall of the right orbit and cribriform plate (Fig. 2). An MR imaging study suggested orbital and cranial invasion (Fig. 3). A systemic workup demonstrated no abnormal findings.

Operation. The patient was taken to the operating room, and endotracheal anesthesia was induced. A standard tracheostomy was performed to secure the airway, provide excellent postoperative pulmonary toilet, and to allow for patient comfort. A lumbar spinal drain was placed. The patient was placed on a three-point pin fixation, and stereotactic registration was performed. Tarsorrhaphy was performed for temporary eyelid closure. The

TABLE 2

Surgery-related complications in patients treated for malignant skull base lesions*

\begin{tabular}{|c|c|c|c|}
\hline \multirow{2}{*}{$\begin{array}{l}\text { Case } \\
\text { No. }\end{array}$} & \multicolumn{3}{|c|}{ Postop } \\
\hline & Complication & Day & Management \\
\hline \multirow[t]{2}{*}{1} & tension pneumocephalus & 4 & $\begin{array}{l}\text { endoscopic nasal pack- } \\
\text { ing, epidural drain }\end{array}$ \\
\hline & transverse sinus thrombosis & 8 & heparinization \\
\hline 2 & tumor bed hematoma & 1 & reop \\
\hline 3 & $\begin{array}{l}\text { pericranial flap failure, pneu- } \\
\text { mocephalus }\end{array}$ & 14 & reop \\
\hline 4 & overpacking of free flap & 4 & $\begin{array}{l}\text { flap liposuction recon- } \\
\text { touring }\end{array}$ \\
\hline 5 & $\begin{array}{l}\text { pericranial flap failure, pneu- } \\
\text { mocephalus, infection }\end{array}$ & 10 & reop \\
\hline 6 & $\begin{array}{l}\text { overdrainage, prolong neuro- } \\
\text { muscular blockade }\end{array}$ & 2 & $\begin{array}{l}\text { discontinue spinal } \\
\text { drain, blood patch }\end{array}$ \\
\hline 7 & $\begin{array}{l}\text { pericranial flap failure, pneu- } \\
\text { mocephalus, epidural hema- } \\
\text { toma }\end{array}$ & 7 & reop \\
\hline 8 & $\begin{array}{l}\text { pericranial flap failure, pneu- } \\
\text { moencephalocele, epidural } \\
\text { hematoma }\end{array}$ & 3 & reop \\
\hline 9 & vasospasm & 7 & triple-H therapy \\
\hline 10 & distal free flap failure & 10 & $\begin{array}{l}\text { debridement on distal, } \\
\text { nonviable flap }\end{array}$ \\
\hline
\end{tabular}

* Triple-H $=$ hypertensive hypovolemic hemodilution.

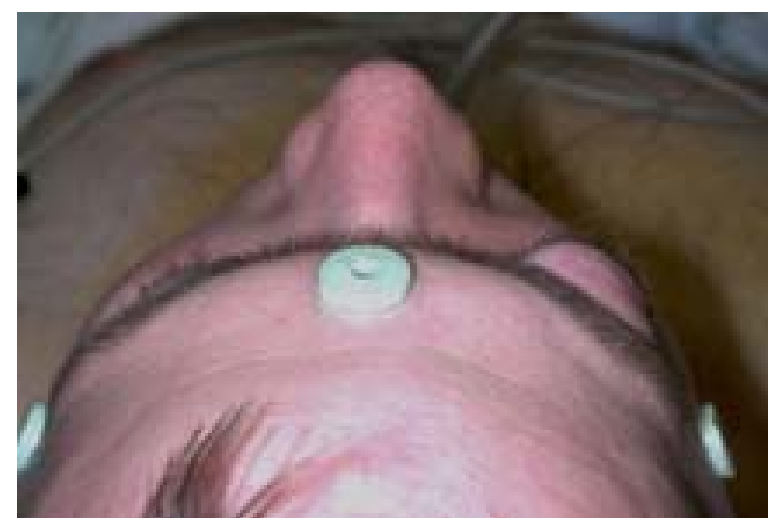

Fig. 1. Preoperative photograph demonstrating exophthalmos of the right eye.

head, face, neck, and abdomen were prepared and draped in a sterile fashion.

A bicoronal skin incision was performed down to, but not including, the temporalis fascia or pericranium. A large vascularized pericranial flap was lifted from temporal line to temporal line and extended 8 to $10 \mathrm{~cm}$ posteriorly. The temporalis fasciae bilaterally were cut to the muscle and brought forward, exposing the entire zygomatic processes. Care was taken to preserve the supraorbital neurovascular structures.

A standard Weber-Fergusson incision was then made; the lip was split, a lateral rhinotomy was made in the nose, and the incisions extended into the conjunctival fornix superiorly and inferiorly, preserving the eyelids for orbital reconstruction. The flap was turned anteriorly, allowing for skeletonization of the hemimaxilla on the right. The flap was then taken laterally to the maxillary tuberosity, and then medially across the hard-soft palate junction, which was divided.

We performed a bifrontal craniotomy, which was followed by a bifrontal supraorbital osteotomy with right zygomatic osteotomy in continuum (Fig. 4). Via a subfrontal extradural approach, microscopic visualization allowed us to observe a tumor breeching the cribriform plate and affixed to the dura. The bone surrounding the right optic canal and medial/superior orbit was drilled away. The dura and the circumferential margin around the por-

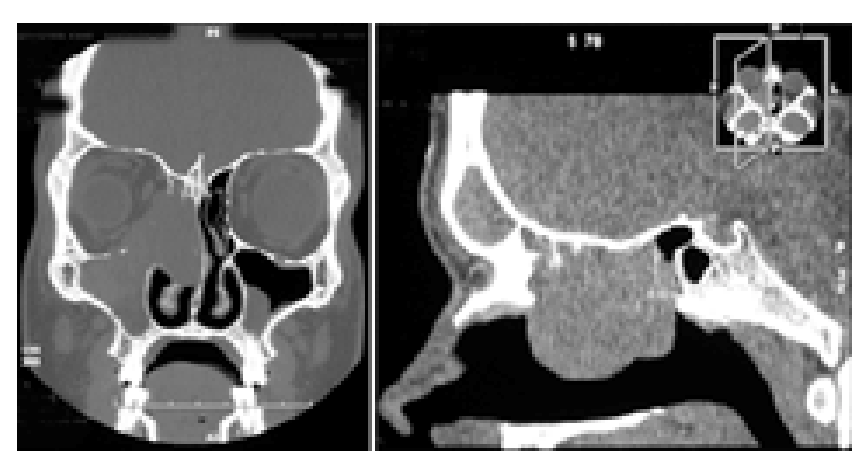

Fig. 2. Left: Coronal CT scan demonstrating invasion of the right orbit. Right: Sagittal reconstruction demonstrating tumor affixed to the cribriform plate. 

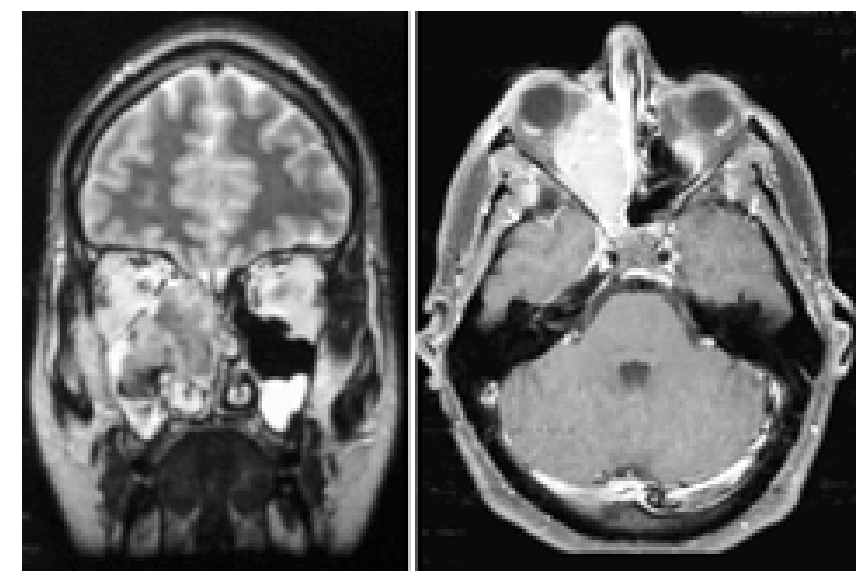

Fig. 3. Left: Coronal $\mathrm{T}_{2}$-weighted $\mathrm{MR}$ image revealing tumor against the dura of the anterior cranial fossa. Right: Axial contrast-enhanced $\mathrm{T}_{2}$-weighted MR image demonstrating invasion of the orbit.

tion of the affixed tumor were opened. The olfactory tracts were cut. Duraplasty of the pericranium was performed. The optic nerve was cut distally in the canal and the dura oversown to avoid CSF leakage. The pericranium was brought down and sutured to the remnant bone (Fig. 5). The distal superior orbital fissure was then transected.

The right superolateral, inferior orbital walls were all resected en bloc with the maxilla, tumor, hard palate, and greater wing of sphenoid (Fig. 6). The excised specimen represented the entire orbitocranial-orbitomaxillary complex (Fig. 7).

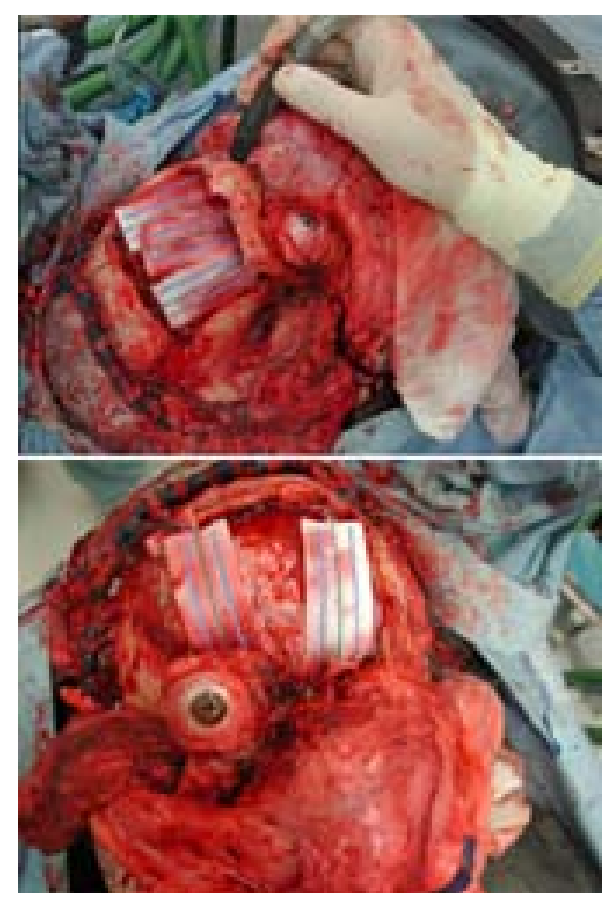

Fig. 4. Upper: Intraoperative photograph obtained after softtissue takedown and bifrontal craniotomy. Lower: Exposure after bifrontal orbital osteotomies and circumferential removal of orbital bone.

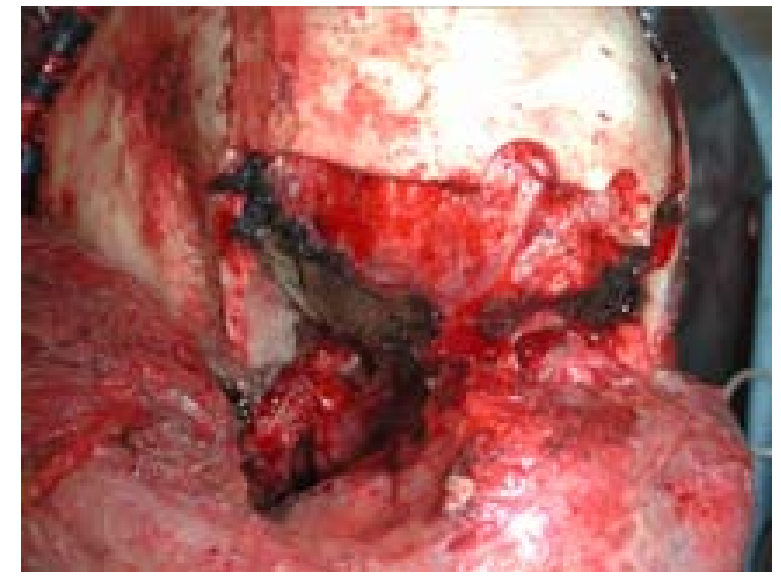

Fig. 5. Intraoperative photograph obtained after resection and prior to pericranial flap rotation.

Microplates and screws were used to close the craniotomy. A rectus abdominus free flap was harvested. Deepithelialization of the skin over the flap was performed, and the skin was placed inward to reconstruct the oral/ nasal wall. Microvascular arterial and venous connections to the facial artery and veins were made in an end-to-end fashion. The flap was positioned and contoured to permit placement of an orbital prosthesis in the future.

Hospital Course. The patient was treated for the first 3 days in the neuroscience intensive care unit and stepdown unit, where use of the drains was discontinued. On Day 4 he was transferred to the floor, and on Day 5 the tracheostomy was decannulated. He was discharged to home on Day 7. The patient then underwent 6 weeks of intensity-modulated three-dimensional conformal radiotherapy (Fig. 8) and concurrent chemotherapy.

\section{DISCUSSION}

\section{Complication Analysis, Avoidance, and Management}

Complication rates for craniofacial resection range from

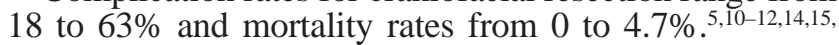
$22,28-30,32-36$ The ability to avoid and manage the associated complications is critical for the successful management of

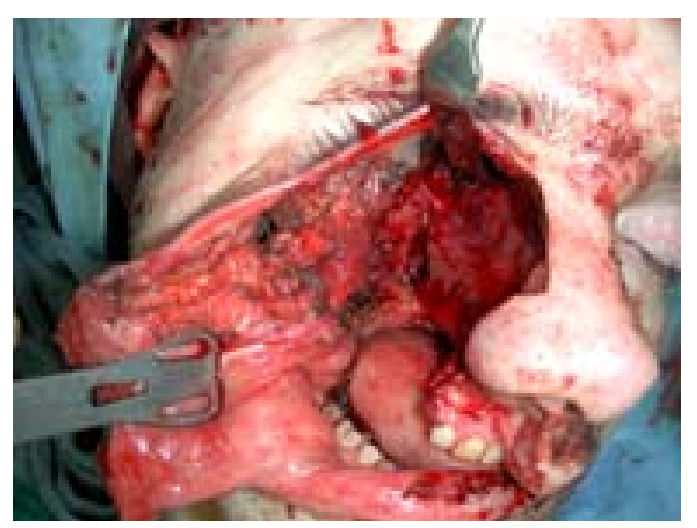

Fig. 6. Intraoperative photograph demonstrating the surgical defect that requires free-flap reconstruction. 


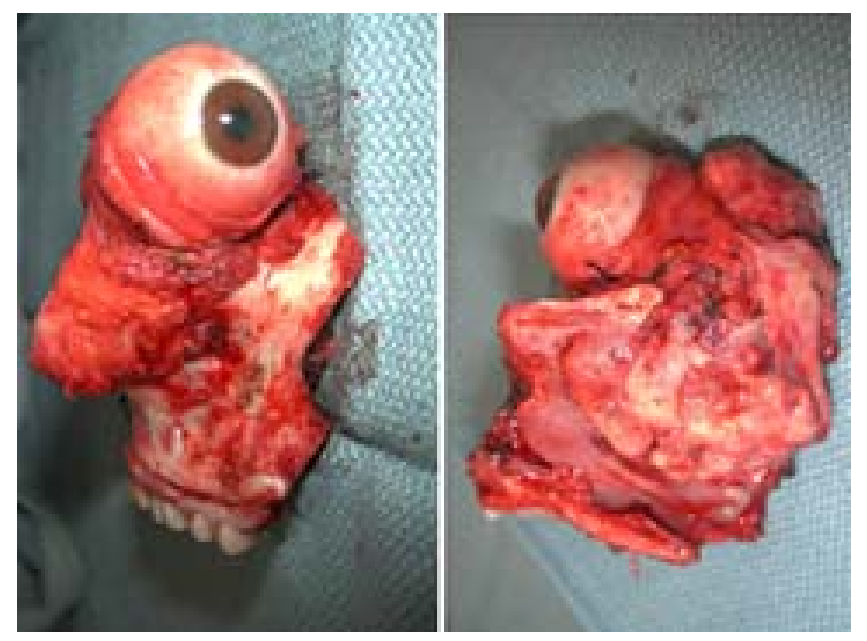

Fig. 7. Left and Right: Photographs showing the entire orbitocranial-orbitomaxillary complex after en bloc resection.

patients with these neoplasms. Common to all approaches is the crossing of the aerodigestive tract-intracranial space interface during the operation. This results in a common set of complications.

Brain Injury. When the supraorbital ridges have been removed, access is provided to a low region at the base of the brain. Keeping the spinal drain closed, and thus the subarachnoid space filled with CSF, confers a concussion buffer during the extradural procedure. Appropriate head extension allows the brain to fall back against gravity, avoiding frontal lobe retraction. Once the cisterns have been microsurgically dissected the frontal lobes are released, and tumor removal and dural closure are facilitated.

Infection. Whenever possible, the intradural compartment prior to gross containment should be sequestered with the aerodigestive tract. The craniotomy should be designed to be superior to the sinus, permitting elevation of the dura and sequestration with antibiotic-soaked Telfa during the orbital and sinus osteotomies. Antibiotic therapy is undertaken using clindamycin irrigation and intravenous ceftriaxone. Epidural and subgaleal drains are placed to close dead space and prevent potential fluids from becoming culture media.

Only after completion of adjuvant therapy should any synthetic materials such as bone cements be considered for use in reconstruction. The operations are lengthy, and highly contaminated fields are exposed. In delaying cosmetic reconstruction, the risk of foreign body contamination is decreased and correction of late cosmetic changes is permitted. Postoperatively, vigilant endoscopic surveillance and nasal hygiene, which should be continued until completion of radiotherapy, allows the onset of late infection complications to be avoided.

\section{Pneumocephalus (Tension)/Dural Banding/CSF Leak}

The use of spinal drainage should be minimized to avoid excessive collapse of the brain. The spinal drain should be removed at the end of the procedure. A patulous overlapping watertight duraplasty should be performed. This allows for free expansion of the brain. If the duraplasty is too tight or the lateral tenting sutures ill placed, brain reexpansion can be restricted. Closure should be reinforced using fibrin glue. The pericranial flap should be positioned inferior to the supraorbital osteotomy and sutured directly to the bone whenever possible. Our experience has taught that in all cases in which there is failure of the pericranial flap, the flap had been brought superior to the ridge and appeared to have undergone infarction secondary to venous outflow obstruction. Pericranial flap failure generally occurs 3 to 7 days postoperatively, manifesting as a new onset of pneumocephalus and presence of epidural blood. An epidural drain should be placed and brought through a separate stab wound. Endoscopic nasal packing composed of fat and fibrin glue is applied, after which nasal trumpets are placed. An epidural drain that holds suction indicates reconstitution and sequestration of the intracranial space; after this has been demonstrated the patient may be taken from the operating room.

Should there be a delayed loss of closure or late-onset pneumocephalus, needle aspiration may be performed through a burr hole. Patients should be returned to the operating room, where endoscopy can be used to guide repacking and placement of an epidural catheter. Intubation or tracheostomy can be used to create airway diversion but this is rarely necessary.

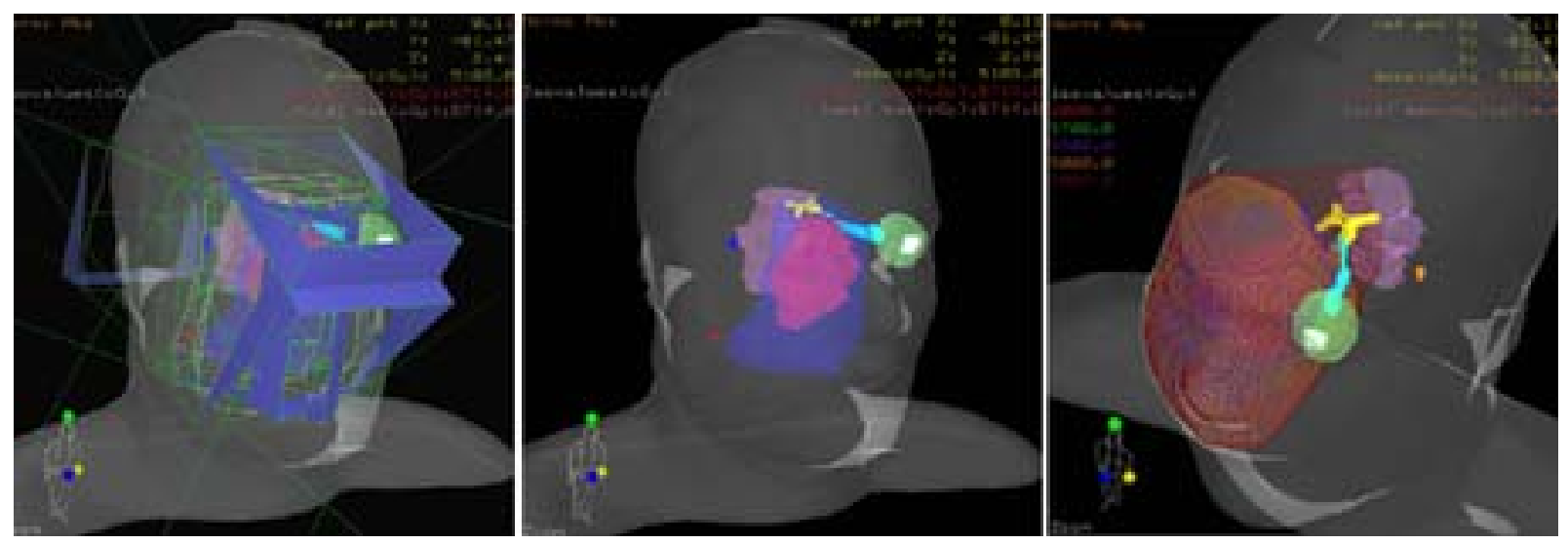

Fig. 8. Left, Center, and Right: Demonstration of three-dimensional conformal intensity-modulated radiotherapy planning. 


\section{CONCLUSIONS}

Acceptable rates of morbidity and mortality are achieved in the surgical oncological management of malignant skull base neoplasms. The surgery-related impact on the natural history of the disease remains under investigation, as do the roles of adjuvant chemo- and radiotherapy. Cranial base approaches provide robust exposure to malignancies of the skull base, allowing for resection. The defects created require complex transfers of adjacent tissue and free flap procedures to restore the immunological barriers, sequester the intracranial compartment, and yield satisfactory volumetric and cosmetic results. Successful management requires a multidisciplinary approach and a postoperative environment in which aggressive management of the associated complications can be performed.

\section{Acknowledgments}

The authors thank Dianne Martia for her editorial skills and Marlene Rakowski for her secretarial assistance.

\section{References}

1. Blacklock JB, Weber RS, Lee YY, et al: Transcranial resection of tumors of the paranasal sinuses and nasal cavity. J Neurosurg 71:10-15, 1989

2. Carrau RL, Synderman C, Janecka IP, et al: Antibiotic prophylaxis in cranial base surgery. Head Neck 13:311-317, 1991

3. Catalano PJ, Hecht CS, Biller HF, et al: Craniofacial resection. An analysis of 73 cases. Arch Otolaryngol Head Neck Surg 120:1203-1208, 1994

4. Clayman GL, DeMonte F, Jaffe DM, et al: Outcome and complications of extended cranial-base resection requiring microvascular free-tissue transfer. Arch Otolaryngol Head Neck Surg 121:1253-1257, 1995

5. Deschler DG, Gutin PH, Mamelak AN, et al: Complications of anterior skull base surgery. Skull Base Surg 6:113-118, 1996

6. Gluckman JL: Craniofacial resection. Ear Nose Throat J 70:595-599, 1991

7. Goffin J, Fossion E, Plets C, et al: Craniofacial resection for anterior skull base tumours. Acta Neurochir 110:33-37, 1991

8. Janecka IP, Nuss DW, Sen CN: Midfacial split for access to the central base. Acta Neurochir Suppl 53:199-203, 1991

9. Johns ME, Winn HR, McLean WC, et al: Pericranial flap for the closure of defects of craniofacial resection. Laryngoscope 91: 952-959, 1981

10. Kraus DH, Shah JP, Arbit E, et al: Complications of craniofacial resection for tumors involving the anterior skull base. Head Neck 16:307-312, 1994

11. Levine PA, Debo RF, Meredith SD, et al: Craniofacial resection at the University of Virginia (1976-1992): survival analysis. Head Neck 16:574-577, 1994

12. Levine PA, Gallagher R, Cantrell RW: Esthesioneuroblastoma: reflections of a 21-year experience. Laryngoscope 109: 1539-1543, 1999

13. McCutcheon IE, Blacklock JB, Weber RS, et al: Anterior transcranial (craniofacial) resection of tumors of the paranasal sinuses: surgical technique and results. Neurosurgery 38: 471-480, 1996

14. Nibu K, Sasaki T, Kawahara N, et al: Complications of craniofacial surgery for tumors involving the anterior cranial base. Neurosurgery 42:455-462, 1998

15. Nuss DW: Prevention of intracranial complications in anterior skull base surgery, in Goebel JA (ed): Insights in Otolaryngology. St Louis: Mosby Year Book, 1992, pp 1-11
16. Origitano TC: The orbitocranial zygomatic approach to aneurysms of the upper basilar trunk, in Rengachary SS, Wilkins RH (eds): Neurosurgical Operative Atlas. Park Ridge, IL: AANS, 1999, pp 87-94

17. Origitano TC, Al-Mefty O, Leonetti JP, et al: En bloc resection of an ethmoid carcinoma involving the orbit and medial wall of the cavernous sinus. Neurosurgery 31:1126-1131, 1992

18. Origitano TC, Petruzzelli GJ: The extended subfrontal transcranial approach for transcranial transdural tumors: surgical technique. Contemp Neurosurg 23:1-8, 2001

19. Panje WR, Dohrmann GJ III, Pitcock JK, et al: The transfacial approach for combined anterior craniofacial tumor ablation. Arch Otolaryngol Head Neck Surg 115:301-307, 1989

20. Petruzzelli GJ, Origitano TC, Stankiewicz JA, et al: Frameless stereotactic localization in cranial base surgery. Skull Base Surg 10:125-130, 2000

21. Raveh J, Laedrach K, Speiser M, et al: The subcranial approach for fronto-orbital and anteroposterior skull-base tumors. Arch Otolaryngol Head Neck Surg 119:385-393, 1993

22. Richtsmeier WJ, Briggs RJ, Koch WM, et al: Complications and early outcome of anterior craniofacial resection. Arch Otolaryngol Head Neck Surg 118:913-917, 1992

23. Scher RL, Cantrell RW: Anterior skull base reconstruction with the pericranial flap after craniofacial resection. Ear Nose Throat J 71:210-217, 1992

24. Schramm VL Jr, Myers EN, Maroon JC: Anterior skull base surgery for benign and malignant disease. Laryngoscope 89: 1077-1091, 1979

25. Sekhar LN, Nanda A, Sen CN, et al: The extended frontal approach to tumors of the anterior, middle, and posterior skull base. J Neurosurg 76:198-206, 1992

26. Sekhar LN, Sen C, Snyderman CH, et al: Anterior, anterolater$\mathrm{al}$, and lateral approaches to extradural petroclival tumors, in Sekhar LN, Janecka IP (eds): Surgery of Cranial Base Tumors. New York: Raven Press, 1993, pp 157-223

27. Sessions RB, Larson DL: En bloc ethmoidectomy and medial maxillectomy. Arch Otolaryngol 103:195-202, 1977

28. Shah JP, Kraus DH, et al: Craniofacial resection for tumors involving the anterior skull base. Otolaryngol Head Neck Surg 106:387-393, 1992

29. Shah JP, Kraus DH, Bilsky MH, et al: Craniofacial resection for malignant tumors involving the anterior skull base. Arch Otolaryngol Head Neck Surg 123:1312-1317, 1997

30. Shah JP, Sundaresan N, Galicich J, et al: Craniofacial resections for tumors involving the base of the skull. Am J Surg 154: $352-358,1987$

31. Snyderman CH, Janecka IP, Sekhar LN, et al: Anterior cranial base reconstruction: role of galeal and pericranial flaps. Laryngoscope 100:607-614, 1990

32. Spetzler RF, Pappas CT: Management of anterior skull base tumors. Clin Neurosurg 37:490-501, 1991

33. Stieg PE, Mulliken JB: Neurosurgical complications in craniofacial surgery. Neurosurg Clin N Am 2:703-708, 1991

34. Terz JJ, Young HF, Lawrence W Jr: Combined craniofacial resection for locally advanced carcinoma of the head and neck II. Carcinoma of the paranasal sinuses. Am J Surg 140: 618-624, 1980

35. Van Tuyl R, Gussack GS: Prognostic factors in craniofacial surgery. Laryngoscope 101:240-244, 1991

36. Wanamaker JR, Mehle ME, Wood BG, et al: Tension pneumocephalus following craniofacial resection. Head Neck 17: 152-156, 1995

Manuscript received April 13, 2002.

Accepted in final form April 30, 2002.

Address reprint requests to: Thomas C. Origitano, M.D., Ph.D., Department of Neurological Surgery, 2160 South First Avenue, Maywood, Illinois 60153. email: torigit@lumc.edu. 